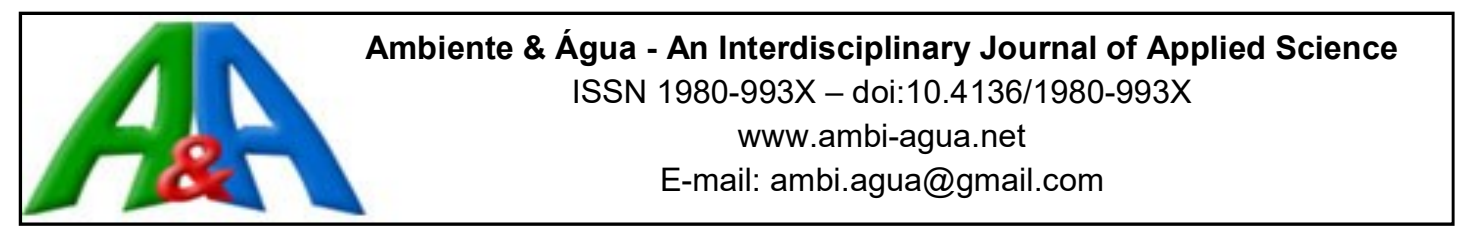

\title{
Avaliação de modelo de balanço hídrico com base na estimativa da recarga potencial
}

\author{
doi:10.4136/ambi-agua.1856
}

Received: 03 Feb. 2016; Accepted: 11 Jul. 2016

\author{
Lucas Machado Pontes ${ }^{1^{*}}$; Gilberto Coelho ${ }^{2}$; Carlos Rogério de Mello ${ }^{2}$; \\ Antônio Marciano da Silva ${ }^{2}$; Geraldo César Oliveira ${ }^{1}$; \\ Marcelo Ribeiro Viola ${ }^{2}$ \\ Universidade Federal de Lavras (UFLA), Lavras, MG, Brasil \\ ${ }^{1}$ Departamento de Ciência do Solo \\ ${ }^{2}$ Departamento de Engenharia \\ *Autor correspondente: e-mail: lucas.pontesm@gmail.com, \\ coelho@deg.ufla.br, crmello@deg.ufla.br,marciano@deg.ufla.br, \\ geraldooliveira@dcs.ufla.br, marcelo.viola@deg.ufla.br
}

\section{RESUMO}

A recarga do aquífero livre é um dos processos mais importantes na hidrologia das águas subterrâneas, pois constitui reserva renovável deste manancial. Portanto, uma boa estimativa desta variável é fundamental para uma gestão adequada dos recursos hídricos, sobretudo frente à variabilidade climática inerente ao regime climático, assim como o avanço da poluição das águas superficiais e aumento da demanda por águas subterrâneas de boa qualidade. No presente trabalho, foi utilizado um modelo de balanço hídrico do solo para estimar a recarga potencial (Rp) do aquífero livre e os demais componentes do ciclo hidrológico. O modelo foi aplicado em duas bacias hidrográficas de cabeceira do Rio Grande, em Minas Gerais: a Bacia Hidrográfica do Ribeirão Lavrinha (BHRL) e a Bacia Hidrográfica do Ribeirão Marcela (BHRM). A BHRL apresentou maiores valores de Rp, com média anual de $895 \mathrm{~mm}$, o que corresponde a $40 \%$ da precipitação média anual, enquanto que na BHRM estes valores foram de $393,3 \mathrm{~mm}$ e $25 \%$, respectivamente. Os valores de escoamento de base confirmam essa maior recarga na BRHL, onde este componente da hidrógrafa correspondeu à $76 \%$ do total escoado, contra $40 \%$ para a BHRM. Com a modelagem empregada, foi possível captar essa diferença, porém seus resultados só foram satisfatórios para um dos anos na BHRL e para todo o período na BHRM, o que reforça a necessidade de utilizar este modelo para longos períodos de tempo.

Palavras-chave: BALSEQ, hidrologia, modelagem.

\section{Water balance model evaluation based on an estimate of potential recharge}

\begin{abstract}
The free aquifer recharge is a process of major importance in groundwater hydrology because it represents the renewable reserves of the water source. A good estimate of this variable is therefore critical to the proper management of water resources, particularly in light of climate variability inherent to the climate regime, as well as the increasing of surface water


pollution and increased demand for good quality water groundwater. This study used a water balance model in soil to estimate the potential recharge (Rp) of the unconfined aquifer and the other components of the hydrological cycle. The model was applied in two watershed headwaters of the Rio Grande in Minas Gerais, Brazil: the Lavrinha River Basin (BHRL) and the Marcela River Basin (BHRM). The BHRL presents higher values of Rp, with an annual average of $895 \mathrm{~mm}$, which corresponds to $40 \%$ of rainfall, while at the BHRM these values were $393.3 \mathrm{~mm}$ and $25 \%$, respectively. The base runoff values confirm the greater recharge in BRHL, where this hydrograph component corresponded to $76 \%$ of the total discharge, compared with $40 \%$ for BHRM. The BALSEQ model allowed us to capture this difference, but the results were satisfactory for only one of the years in the BHRL and for the entire period for the BHRM, which reinforces the need to use this model for long time periods.

Keywords: BALSEQ, hydrology, modeling.

\section{INTRODUÇÃO}

As águas subterrâneas representam o principal manancial de águas doces no mundo e sua recarga depende da infiltração e percolação da água no solo. Além disso, o solo serve também como filtro e regulador do fluxo de água nas nascentes e, por conseguinte, nos cursos d'água. A compreensão dos complexos processos de interação entre águas superficiais e subterrâneas é a chave para uma gestão adequada dos recursos hídricos (Price, 2011).

Dentre esses processos, a recarga hídrica é a variável de maior destaque. Se devidamente estimada, pode servir de base para o uso sustentável dos aquíferos, desde que o volume anual explotado seja menor que a recarga anual. Além disso, o aquífero livre é responsável pela regularização da vazão nos cursos d'água por meio do escoamento de base no período de estiagem. A complexidade e onerosidade do monitoramento dos movimentos da água subterrânea inviabiliza obter estimativas precisas da recarga em bacias hidrográficas. Uma alternativa válida é a modelagem, diversos tipos de modelos hidrológicos são usados para estimar a recarga (Cuthbert et al., 2013).

Os modelos mais simples e utilizados são os de balanço hídrico, que consistem no saldo entre as entradas e saídas da água no sistema. O BALSEQ (Lobo-Ferreira, 1981) é um modelo de balanço hídrico sequencial diário, com ênfase no solo e na estimativa da recarga potencial do aquífero livre. Sua simplicidade e versatilidade permitiram que fosse aplicado em diversas condições de clima, solo e vegetação (Camargo et al., 2011). Faltam, no entanto, trabalhos que verifiquem a qualidade de seus resultados.

A validação de modelos hidrológicos é uma parte fundamental da modelagem, que visa aferir sobre a qualidade das informações geradas nas simulações hidrológicas. Isto normalmente é feito com o uso de coeficientes de eficiência, que comparam dados simulados com os dados medidos em campo. Porém, medidas diretas de recarga permanecem tecnicamente inviáveis para bacias hidrográficas reais, mesmo que pequenas (Chung et al., 2010).

Assim, a validação dos dados simulados com modelos como o BALSEQ tem que ser feita por meio de comparações indiretas entre a estimativa da recarga e dados de vazão do curso d'água ou medidas de variação do nível freático, entre outros. A recarga potencial é definida como o conteúdo de água no solo que percola para além da zona radicular, ou seja, deixa de estar disponível para a evapotranspiração e pode percolar até a zona saturada, caracterizando a recarga efetiva (Perkins et al., 2014).

A Região do Alto Rio Grande é estratégica para as bacias a jusante pois apresenta importantes nascentes que abastecem mananciais urbanos, represas com potencial de produção de energia elétrica e diversas atividades agrícolas. O escoamento de base é o 
responsável natural pela manutenção de cursos d'água perenes no período de estiagem, portanto, deve ser priorizado nas ações de manejo dos recursos hídricos (Price, 2011).

Os objetivos deste trabalho foram estimar a recarga do aquífero livre para duas bacias hidrográficas características da região do Alto Rio Grande, no bioma Mata Atlântica, e avaliar o modelo BALSEQ como instrumento de predição da recarga potencial e dos demais componentes do balanço hídrico para diferentes condições pedogeomorfológicas e de uso e ocupação do solo.

\section{MATERIAL E MÉTODOS}

\section{1. Áreas de estudo}

Foram utilizados dados de duas bacias hidrográficas monitoradas, inseridas na Unidade de Planejamento e Gestão de Recursos Hídricos do Alto Rio Grande (UPGRH - GD1), sul de Minas Gerais (Figura 1).

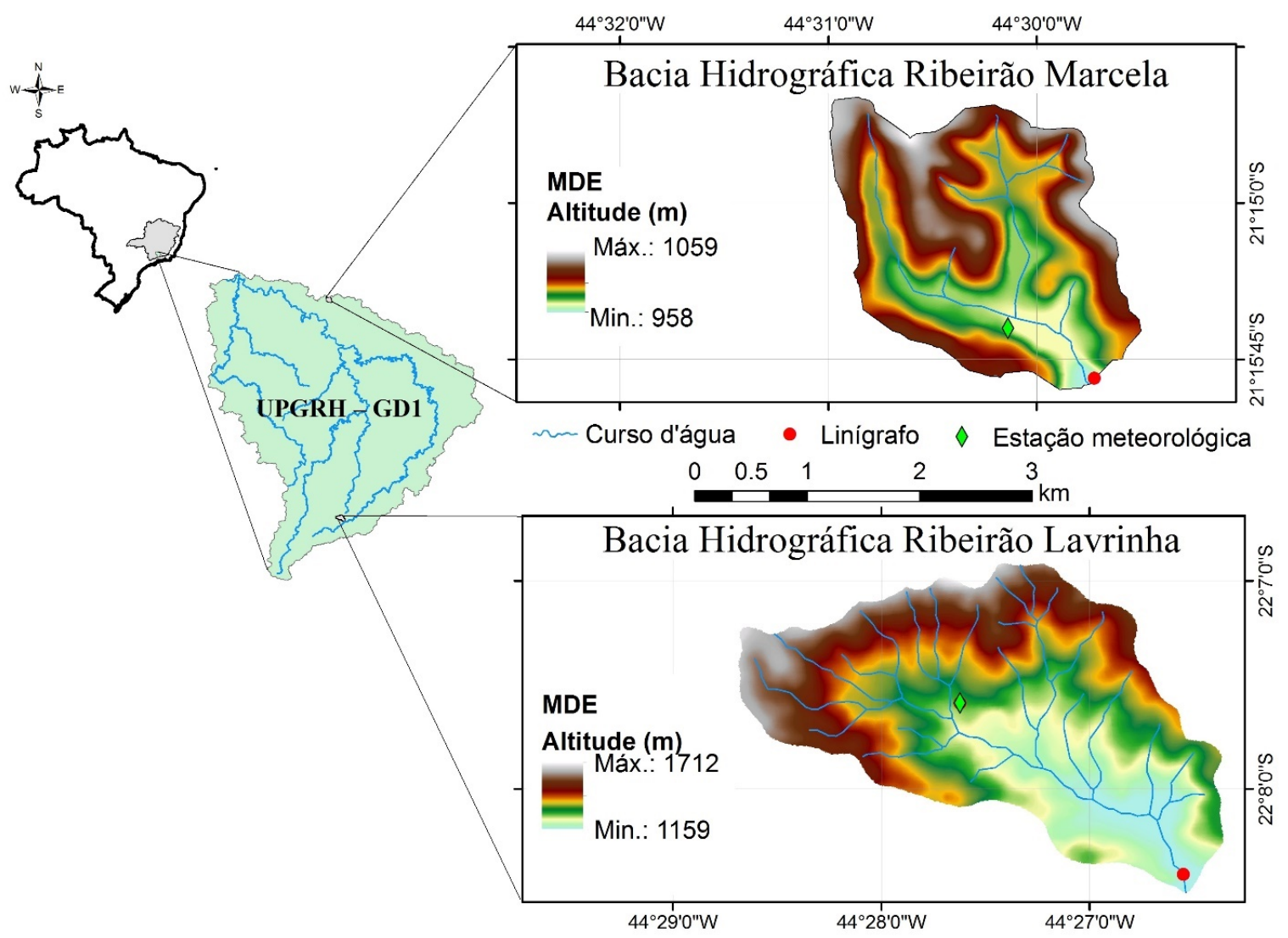

Figura 1. Localização da Unidade de Planejamento e Gestão de Recursos Hídricos do Alto Rio Grande (UPGRH - GD1) e das bacias hidrográficas do Ribeirão Lavrinha (BHRL) e do Ribeirão Marcela (BHRM) com os respectivos modelos digitais de elevação (MDE).

O monitoramento da vazão nas bacias foi feito com uso de linígrafos automatizados na seção de saída dos cursos d'água nas respectivas bacias, e das chuvas, com pluviógrafos automáticos.

A Bacia Hidrográfica do Ribeirão Lavrinha (BHRL) está localizada entre as coordenadas geográficas $22^{\circ} 06^{\prime} 50,4^{\prime \prime}$ e e $22^{\circ} 08^{\prime} 24,0^{\prime \prime}$ de latitude Sul e $44^{\circ} 26^{\prime} 20,4^{\prime \prime}$ e $44^{\circ} 28^{\prime} 40,8^{\prime}$ ' de longitude Oeste, no município de Bocaina de Minas. Essa bacia drena uma área de 676 ha, 
com altitude e declividade médias de $1.375 \mathrm{~m}$ e 38,5\%, respectivamente. O ribeirão deságua diretamente no Rio Grande. O clima da BHRL foi classificado como do tipo Cwb (temperado quente), conforme classificação de Köppen (Alvares et al., 2013), caracterizado como mesotérmico de verões brandos e suaves e estiagem no inverno. A precipitação média anual é de $1.860 \mathrm{~mm}$ e a temperatura média anual é de $17,5^{\circ} \mathrm{C}$. A declividade, as classes de solos e os tipos de uso e ocupação do solo na BHRL estão representados na Figura 2.
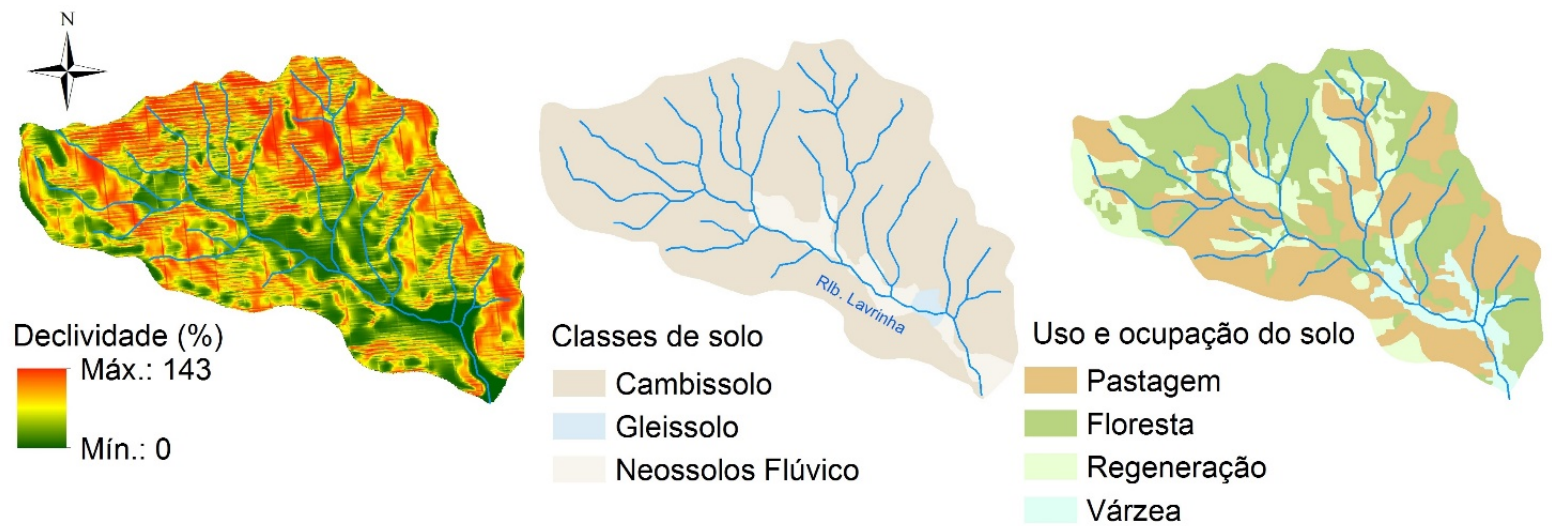

Figura 2. Declividade, classes de solo e uso e ocupação dos solos na BHRL.

Fonte: adaptado de Ávila et al. (2010).

A Bacia Hidrográfica do Ribeirão Marcela (BHRM) está localizada entre as coordenadas

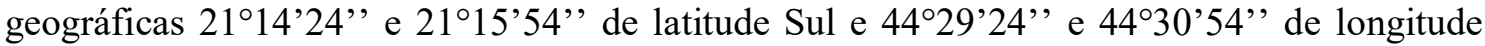
Oeste, no município de Nazareno, MG. Drena uma área de 470 ha, à margem direita do córrego Jaguara, com altitude e declividade médias de $1.007 \mathrm{~m}$ e 12,3\%, respectivamente. $\mathrm{O}$ clima na BHRM é do tipo Cwa, conforme a classificação Köppen (Alvares et al., 2013), caracterizado como temperado com verões quentes e úmidos e invernos secos. A precipitação e a temperatura média anual são de $1.300 \mathrm{~mm}$ e $19,7^{\circ} \mathrm{C}$, respectivamente. A declividade, as classes de solos e os tipos de uso e ocupação do solo na BHRM estão representados na Figura 3.
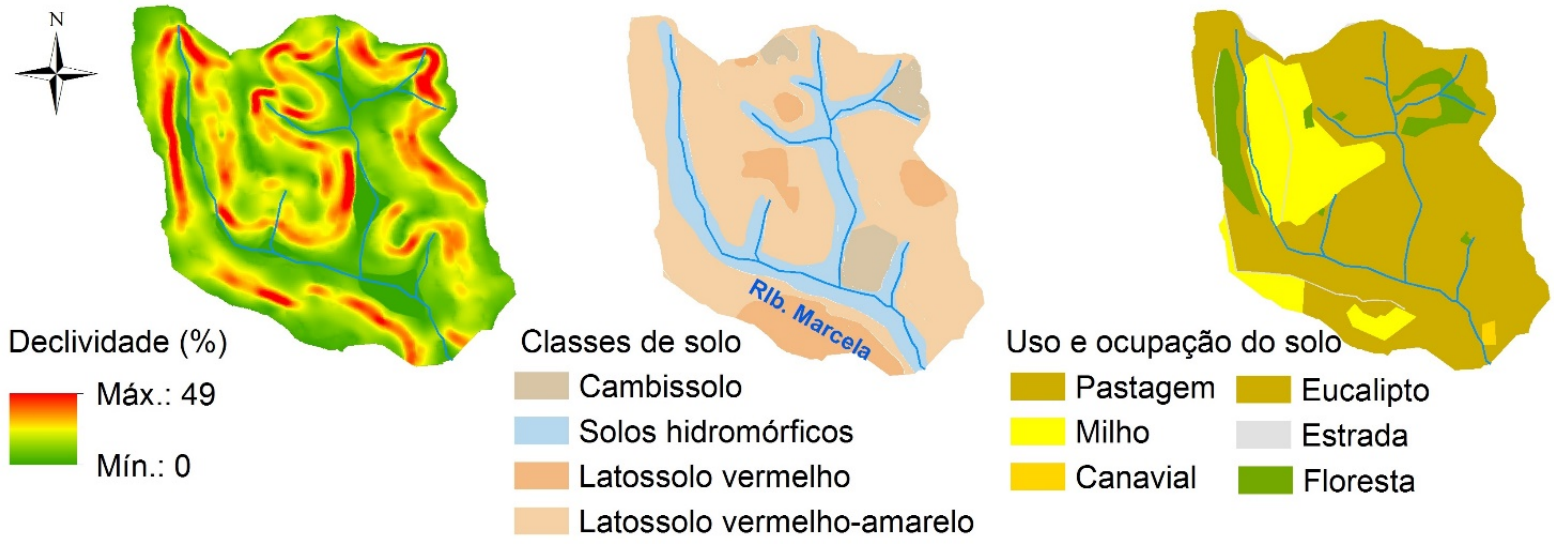

Figura 3. Declividade, classes de solo e uso e ocupação dos solos na BHRM.

Fonte: Gomes et al. (2008).

\subsection{Separação dos escoamentos na hidrógrafa}

Para a obtenção do escoamento de base a partir da hidrógrafa foi utilizado o filtro numérico com dois parâmetros: $\alpha$ e $\mathrm{BFI}_{\max }$, proposto por Eckhardt (2005) (Equação 1). 


$$
\mathrm{EB}_{\mathrm{i}}=\frac{(1-\mathrm{B} \max ) \cdot \propto \cdot \mathrm{EB}_{\mathrm{i}-1}+(1-\propto) \cdot \mathrm{BFI}_{\max } \cdot \mathrm{Q}_{\mathrm{i}}}{1-\propto \cdot \mathrm{BFI}_{\max }}
$$

em que:

EBi é o escoamento de base $\left(\mathrm{m}^{3} \mathrm{~s}^{-1}\right)$;

Qi é a vazão $\left(\mathrm{m}^{3} \mathrm{~s}^{-1}\right)$;

$\alpha$ é a constante de depleção do escoamento $\left(\mathrm{d}^{-1}\right)$;

$\mathrm{BFI}_{\max }$ é a fração máxima que o escoamento de base representa em relação à vazão (decimal).

A solução da Equação 1 está de acordo com a metodologia descrita em Eckhardt (2005), e os índices $\propto \mathrm{e} \mathrm{BFI}_{\max }$ foram estimados conforme metodologia proposta por Collischonn $\mathrm{e}$ Fan (2012).

\subsection{Balanço hídrico estimado com o BALSEQ}

O BALSEQ é um modelo concentrado, de tempo contínuo, que pode ser aplicado para condições nas quais não exista recarga artificial, não haja escoamento superficial afluente à área de estudo, o nível freático se encontre sempre abaixo da profundidade do solo sujeito à evapotranspiração, não haja zonas de impedimento abaixo do solo e nem caminhos preferenciais da água no solo (Camargo et al., 2011). Atendidas essas considerações a equação do balanço hídrico para o solo nessa área pode ser expressa pela (Equação 2).

$$
P-E T R-D A i-E S-R p=\varepsilon
$$

em que:

P é a precipitação (mm);

ETR é a evapotranspiração real (mm);

DAi é a variação (final - inicial) do armazenamento de água no solo (mm);

ES é o escoamento superficial (mm);

Rp é a recarga potencial (mm); e,

$\varepsilon$ é o erro de cálculo do balanço.

Para a aplicação sequencial desta fórmula, é necessário conhecer os valores de $\mathrm{P}$ e da evapotranspiração de referência $\left(\mathrm{ET}_{0}\right)$ para cada intervalo de tempo do balanço, assim como o valor da lâmina d'água total armazenada no solo (CTarm) (Equação 3).

$$
\text { CTarm }=C C * \text { Prof } * D s * 10^{-1}
$$

em que:

CTarm é a capacidade total de armazenamento na zona radicular ( $\mathrm{mm})$;

CC é a umidade na capacidade de campo do solo (g. $\left.\mathrm{g}^{-1}\right)$;

Ds é a densidade do solo $\left(\mathrm{g} . \mathrm{cm}^{-3}\right) \mathrm{e}$

Prof é a profundidade do solo sujeita à evapotranspiração $(\mathrm{cm})$.

O ICV foi inserido como uma modificação do modelo geral. A precipitação diária é subtraída pela ICV e, quando esta é maior que a precipitação, o valor da precipitação considerado é nulo. A evapotranspiração potencial (ETP) é dada pela multiplicação entre $\mathrm{ET}_{0}$ e Kc, já a evapotranspiração real será menor ou igual à lâmina d'água armazenada, quando 
esta for maior ou igual a ETP, caso contrário a ETR será igual à ETP.

Para a estimativa do escoamento superficial foi utilizado o Método do Número da Curva (CN-SCS) desenvolvido pelo Soil Conservation Service (Mockus, 1972). As áreas da bacia com a presença de Gleissolos e Neossolos Flúvicos, e as áreas de corpos d'água não foram consideradas na aplicação do modelo para estimar a Rp. Estes solos são caracterizados como áreas de descarga do aquífero, por isso, não contribuem diretamente para a recarga do aquífero livre, já que o nível freático é superficial nessas áreas. No entanto, são áreas importantes na geração de escoamento superficial e, assim, as estimativas de ES para essas áreas foram contabilizadas no balanço total da bacia hidrográfica.

O ES estimado com o BALSEQ foi calibrado no modelo com os dados de Lâmina de Escoamento Superficial (LES) obtidos na separação dos escoamentos na hidrógrafa. A calibração baseou-se na maximização do Coeficiente de Nash-Sutcliffe $\left(\mathrm{C}_{\mathrm{NS}}\right)$ (Schaefli e Gupta, 2007) pela otimização dos parâmetros de entrada para os quais o modelo mostrou-se mais sensível, de modo que a diferença entre os dados simulados e medidos fosse mínima.

A calibração foi feita variando o $\mathrm{CN}$ e o Índice de Cobertura Vegetal (ICV), pois estes foram os parâmetros mais significativos para o ES e para a $\mathrm{Rp}$ segundo análise de sensibilidade apresentada no trabalho de Pontes et al. (2015). Portanto, o CN foi usado para calibrar o modelo quanto ao escoamento superficial, e o ICV foi incorporado para áreas com vegetação arbórea, como modificação do modelo original. O ICV refere-se à fração da precipitação que é interceptada pelo dossel das coberturas florestais e volta para a atmosfera como evaporação.

Os valores, para cada um dos parâmetros de entrada do modelo, foram inicialmente atribuídos de acordo com o levantamento geológico, pedológico e do uso e cobertura do solo nas bacias hidrográficas estudadas. Os parâmetros referentes aos solos: CC e Ds, foram obtidos pela média dos valores encontrados para cada combinação de solo e vegetação mapeados. Os parâmetros referentes à vegetação: coeficiente de cultura $(\mathrm{Kc})$, Prof. e ICV, foram adotados de acordo com dados da literatura (Tabela 1).

Tabela 1. Valores dos parâmetros de entrada do modelo BALSEQ.

\begin{tabular}{lccc}
\hline Cobertura vegetal & $\mathrm{K}_{\mathrm{c} \text { mid }}$ & $\begin{array}{c}\text { Prof. } \\
(\mathrm{m})\end{array}$ & $\begin{array}{c}\text { ICV } \\
(\%)\end{array}$ \\
\hline Pastagem & 0,80 & 0,30 & - \\
Floresta & 1,00 & 3,00 & $20 \%$ \\
Eucalipto & 1,00 & 2,00 & $15 \%$ \\
Regeneração & 1,00 & 1,00 & $10 \%$ \\
Milho & 1,20 & 1,00 & - \\
Cana-de-açúcar & 1,25 & 1,20 & - \\
\hline $\begin{array}{l}\text { Kc } c_{\text {mid }} \text { é o coeficiente de cultura } \\
\text { crescimento. Fonte: Allen et al. (1998). }\end{array}$
\end{tabular}

\subsection{Avaliação do modelo}

A avaliação do modelo foi feita com base na comparação dos valores de ES obtidos pelo BALSEQ com os dados de vazão do curso d'água na secção de controle de cada uma das bacias estudadas após a separação do ES na hidrógrafa. Para isto, foram utilizados o Coeficiente de Nasch-Sutcliffe (Cns) (Schaefli e Gupta 2007) e o percentual de viés (Pbias). O período de calibração foi de 2006 a 2008 e a validação foi de 2008 a 2010.

A avaliação qualitativa foi realizada pela comparação gráfica entre os valores simulados 
e os dados medidos. Para facilitar a interpretação e prover uma boa referência para comparação, utilizaram-se gráficos dos valores mensais do ES simulado e observado, bem como dados anuais do EB, em comparação à recarga potencial anual obtida pelo modelo.

A avaliação gráfica da Rp versus Escoamento Base (EB) no tempo é fundamental para verificar a precisão do modelo, pois ela permite estudar a dinâmica temporal dos resultados, facilita a identificação da ocorrência de padrões de erro e oferece uma ideia da sua magnitude.

\section{RESULTADOS E DISCUSSÃO}

\subsection{Separação dos componentes do escoamento}

Os escoamentos de base (EB) e superficial (ES) para os anos hidrológicos compreendidos entre 2006 a 2010 estão apresentados na Tabela 2 na forma de lâmina d'água $(\mathrm{mm})$.

Tabela 2. Precipitação total anual (P) e lâmina de escoamento total (LET) observados e, lâmina de escoamento superficial (LES) e lâmina de escoamento base (LEB) obtidos com a separação das hidrógrafas na BHRL e BHRM.

\begin{tabular}{lccccccc}
\hline Ano hidrológico & $\begin{array}{c}\text { P } \\
(\mathrm{mm})\end{array}$ & $\begin{array}{c}\text { LET } \\
(\mathrm{mm})\end{array}$ & $\begin{array}{c}\text { LES } \\
(\mathrm{mm})\end{array}$ & $\begin{array}{c}\text { LEB } \\
(\mathrm{mm})\end{array}$ & LEB/P & LES/LET & LEB/LET \\
\hline $2006-2007$ & 2003 & 932,5 & 354,3 & 578,1 & 0,29 & 0,38 & 0,62 \\
$2007-2008$ & 2363 & 846,6 & 169,3 & 677,3 & 0,29 & 0,20 & 0,80 \\
$2008-2009$ & 2478 & 868,6 & 95,6 & 773,0 & 0,31 & 0,11 & 0,89 \\
$2009-2010$ & 1984 & 810,8 & 210,8 & 600,0 & 0,30 & 0,26 & 0,74 \\
Média & 2207 & 864,6 & 207,5 & 657,1 & 0,30 & 0,24 & 0,76 \\
C.V. & 0,11 & 0,06 & 0,52 & 0,13 & 0,04 & 0,48 & 0,15 \\
\hline & & & \multicolumn{7}{c}{ BHRM } & & & \\
\hline $2006-2007$ & 1415 & 604 & 404,7 & 199,3 & 0,14 & 0,67 & 0,33 \\
$2007-2008$ & 1458 & 298 & 143,0 & 154,9 & 0,11 & 0,48 & 0,52 \\
$2008-2009$ & 1892 & 717 & 494,7 & 222,3 & 0,12 & 0,69 & 0,31 \\
$2009-2010$ & 1580 & 613 & 349,4 & 263,6 & 0,17 & 0,57 & 0,43 \\
Média & 1587 & 558 & 267,8 & 223,2 & 0,14 & 0,48 & 0,40 \\
C.V. & 0,14 & 0,32 & 0,56 & 0,20 & 0,19 & 0,42 & 0,24 \\
\hline
\end{tabular}

Nota: C.V. é o coeficiente de variação.

Na BHRL nota-se, em todos os anos, um amplo predomínio do EB na vazão do curso d'água, com média de $30 \%$ na razão $\mathrm{LEB} / \mathrm{P}$. Também se pode observar a baixa variação interanual do EB, mesmo com alta variabilidade do total precipitado. Outra observação importante é a relação LEB/LET que nesta bacia hidrográfica foi, em média, igual a 76\%, o que reflete a alta recarga presente da BHRL.

Para a BHRM, a razão LEB/P apresentou média de 13\%, valor este bem menor que o observado na BHRL. Ao comparar os resultados da relação LEB/LET na Tabela 2, fica evidente a maior participação do escoamento de base na vazão do Ribeirão Lavrinha do que no Ribeirão Marcela. Tal fato é devido, em primeiro lugar, ao maior excedente hídrico 
presente na BHRL em relação à $B H R M$, ou seja, a diferença entre a precipitação e a evapotranspiração é maior na primeira bacia. Outro importante fator é a presença de solos mais permeáveis e pedoformas côncavo-côncavas na BHRL que favorecem a infiltração da água e seu movimento subsuperficial, o que potencializa a recarga e a participação do escoamento base na vazão do ribeirão. Além disso, a vegetação nativa mais preservada na BHRL protege o solo da erosão e diminui o escoamento superficial, além de melhorar as condições físico-hídricas do solo, o que evidencia o maior potencial de recarga do aquífero livre na BHRL (Oliveira et al., 2014).

Oliveira et al. (2014), ao separarem os componentes das hidrógrafas do ano hidrológico 2009 - 2010 para a BHRL e para a BHRM, bem como em quatro nascentes em cada uma das bacias, encontraram, para a BHRL, uma LET de $820 \mathrm{~mm}$ e relação LEB/LET de 82,3 \% com LEB igual a $675,2 \mathrm{~mm}$. Para as nascentes da BHRL, Oliveira et al. (2014) estimaram uma LEB média de $698,7 \mathrm{~mm}$, valor superior ao encontrado no presente trabalho, mas que está dentro da variação normal para estas variáveis, conforme o coeficiente de variação (C.V.) aqui calculado.

Na BHRM, Oliveira et al. (2014) obtiveram uma LET de 609,2 mm e LEB de 388,7 mm, com relação LEB/LET de $63,8 \%$, valor este superior ao estimado no presente estudo, o que pode ser devido a diferenças nos métodos de separação da hidrógrafa. A relação LEB/LET encontrado nas nascentes foi, em média, igual a $26 \%$, o que corrobora com a afirmação de que o resultado foi superestimado para a bacia como um todo. O fato é que o escoamento base na BHRL apresenta uma fração $15 \%$ maior na vazão do curso d'água do que na BHRM. Tal fato pôde ser estimado no balanço hídrico executado com o BALSEQ.

\subsection{Balanço hídrico estimado com o BALSEQ}

Os resultados dos componentes do balanço hídrico estimado com o BALSEQ também foram sintetizados em base anual (Tabela 3 ).

Tabela 3. Precipitação anual observada $(\mathrm{P})$ e resultados do balanço hídrico com o BALSEQ na BHRL e na BHRM.

\begin{tabular}{lcccc}
\hline Ano hidrológico & P (mm) & ETR $(\mathrm{mm})$ & ES $(\mathrm{mm})$ & Rp $(\mathrm{mm})$ \\
\hline \multicolumn{5}{c}{ BHRL } \\
\hline $2006-2007$ & 2003 & 1138 & 166,1 & 714,5 \\
$2007-2008$ & 2363 & 1140,9 & 209,5 & 887,8 \\
$2008-2009$ & 2478 & 1139,0 & 227,3 & 1093,6 \\
$2009-2010$ & 1984 & 1119,3 & 148,6 & 884,3 \\
Média & 2207 & 1134,3 & 187,9 & 895,0 \\
\hline & \multicolumn{5}{c}{ BHRM } \\
\hline $2006-2007$ & 1415 & 845,9 & 212,5 & 339,3 \\
$2007-2008$ & 1458 & 901,3 & 163,3 & 358,6 \\
$2008-2009$ & 1892 & 941,7 & 264 & 497,7 \\
$2009-2010$ & 1580 & 926,3 & 326,2 & 377,6 \\
Média & 1587 & 903,8 & 241,5 & 393,3 \\
\hline
\end{tabular}


Na BHRL, observa-se uma grande participação da recarga no balanço hídrico, com 35\% a $44 \%$ da precipitação convertida em recarga potencial, mesmo para uma bacia hidrográfica com as características da Lavrinha, de solos rasos e pouco desenvolvidos (Cambissolos) e relevo fortemente acidentado que, normalmente, indicam um alto índice de escoamento superficial. Porém, elevadas taxas de infiltração e recarga são comumente encontradas em regiões montanhosas sob Mata Atlântica, o que tem sido atribuído sobretudo às condições da cobertura vegetal e condicionamento das camadas superficiais do solo como: acúmulo de matéria orgânica, formação de caminhos preferenciais, maior estruturação do solo, maior porosidade e menor densidade (Price, 2011; Perkins et al., 2014). Além disso, na BHRL, as pedoformas desta bacia hidrográfica com predomínio de feições côncavo-côncavas favorecem o escoamento subsuperficial e, por conseguinte, o predomínio do escoamento de base na vazão do curso d'água (Gomes et al., 2012).

O ES estimado para a BHRL representou pequena parcela do balanço hídrico, o que se deve, sobretudo, ao predomínio da cobertura florestal na bacia. A mata ombrófila tem um alto índice de interceptação da precipitação, o que diminui drasticamente a energia cinética das gotas sobre o solo e o escoamento direto pela superfície. Isso porque a maior parte da água interceptada volta à atmosfera como evaporação e apenas uma parcela muito pequena escoa pelos troncos das árvores e infiltra no solo por caminhos preferenciais formados pelas raízes, ou por outros processos pedológicos. Essa parcela que escoa pelos troncos foi ignorada na modelagem, pois é um processo de difícil simulação e pouca contribuição na recarga, já que apenas $1 \%$ a $2 \%$ da água interceptada escoa pelos troncos (Perez-Marin e Menezes, 2008).

Devido à interceptação de $20 \%$ da precipitação pela cobertura vegetal, houve um aumento médio de $18,8 \%$ na ETR anual média para esta bacia hidrográfica. Portanto, cerca de $51 \%$ da precipitação retorna à atmosfera como evapotranspiração.

Na Bacia Hidrográfica do Ribeirão Marcela, o componente com maior participação no balanço hídrico foi a ETR, com 56,7\% da precipitação na média geral; a recarga potencial e o escoamento superficial representaram $25,15 \%$ e $15,45 \%$, respectivamente. Essa elevada participação da ETR no balanço hídrico se deve, sobretudo, à menor pluviosidade, quando comparada à BHRL, com consequente menor excedente hídrico, recarga e menor capacidade de manutenção dos cursos d'água.

A recarga potencial estimada representa, em média, $24,7 \%$ da precipitação, ou seja, cerca de $15 \%$ menos do que o encontrado na BHRL. Comparação coincidente com os resultados da separação do escoamento base, e que ajuda na validação da modelagem.

Silva et al. (2012) encontraram estimativas de recarga de $11,32 \%$ e $11,79 \%$ da precipitação para duas nascentes localizadas na BHRM, inferiores aos 24,7\% encontrados como média no presente trabalho, o que pode ser devido à subestimativa do rendimento específico, conforme relatado pelo autor. É importante ressaltar que Silva et al. (2012) encontraram valores de recarga maiores para a BHRL do que para a BHRM, do mesmo modo que no presente trabalho e nos demais que foram publicados a respeito destas áreas.

A menor recarga atribuída à BHRM parece se dar, principalmente, devido à menor pluviosidade e consequente menor excedente hídrico, quando comparado à BHRL. Porém, o predomínio de pedoformas convexas, aliado ao histórico de uso, ocupação e manejo da área, também contribui para uma menor recarga do aquífero livre. A pedoforma convexo-côncava favorece o fluxo difuso do escoamento superficial, o que ajuda a explicar a maior participação da evapotranspiração no balanço hídrico e, por conseguinte, menor Rp e EB. Ademais, o manejo historicamente adotado na bacia prejudica a estrutura do solo com diminuição da porosidade devido à compactação e consequente menor permeabilidade, o que afeta negativamente o processo de recarga. Por outro lado, o escoamento superficial é favorecido pela diminuição da porosidade, fato evidenciado pela comparação dos dados medidos em campo com as estimativas obtidas com o BALSEQ. 


\subsection{Avaliação do modelo}

A recarga potencial estimada com o BALSEQ deve ser sempre superior ao escoamento base, isso porque a recarga potencial é a lâmina de água que percolou para além da zona das raízes, mas que não necessariamente chega até a zona saturada (recarga efetiva) para, posteriormente, converter-se em EB. Na BHRL, o relevo movimentado e as pedoformas côncavas favorecem o fluxo acumulado da água e o seu escoamento subsuperficial, o qual pode ser contabilizado como escoamento superficial direto na separação dos elementos da hidrógrafa, aumentando a diferença entre a Rp estimada com o BALSEQ e o EB obtido com as hidrógrafas (Figura 4).

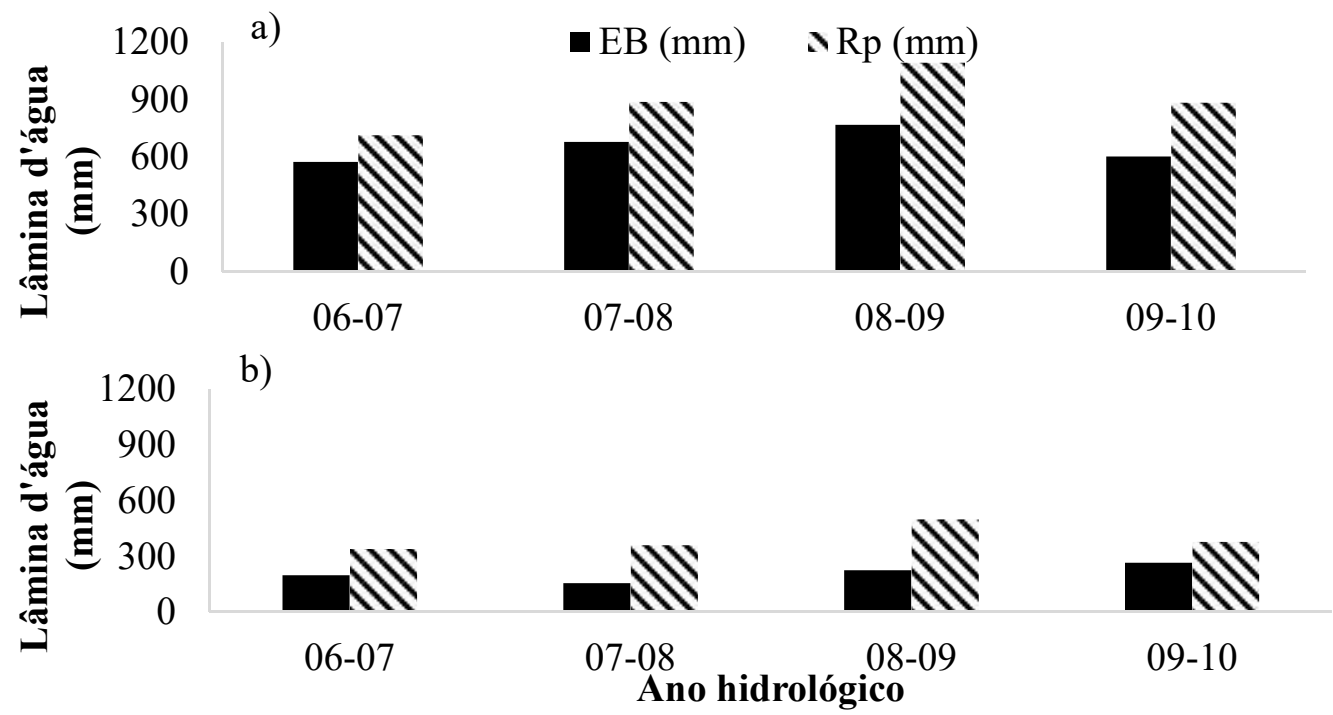

Figura 4. Comparação entre Rp estimada e EB da hidrógrafa na (a) BHRL e na (b) BHRM.

De modo geral, observa-se um bom ajuste da modelagem na BHRL, já que o BALSEQ acompanhou o comportamento do EB com a estimativa da Rp, ou seja, existe coerência entre os dados de escoamento base e a simulação com o BALSEQ. Porém, como o ano hidrológico 2008-2009 teve um total precipitado acima da média, observa-se um aumento da diferença entre a Rp obtida pelo BALSEQ e o EB. O mesmo efeito foi identificado também no ano posterior, quando o total precipitado foi menor, porém, as condições de umidade do solo estavam elevadas por causa dos eventos do ano anterior.

Já na BHRM, a diferença entre EB e Rp deve-se ao armazenamento da água no solo em profundidades abaixo da zona das raízes, isso porque nesta bacia predominam os Latossolos, que têm elevada capacidade de armazenamento da água no solo. Ou, é devida à redistribuição da umidade no perfil do solo acompanhando o relevo, de modo a tornar-se disponível à evapotranspiração por causa da pedoforma convexo-côncava, que atua no fluxo divergente das águas, favorecendo a ETR, o que diminui ainda mais o excedente hídrico, a recarga e o escoamento base.

$\mathrm{Na}$ BHRM, os valores absolutos de $\mathrm{Rp}$ não acompanharam tão fielmente o comportamento do EB. No ano hidrológico 2007-2008 o EB apresenta queda de 3,4\%, enquanto a $\mathrm{Rp}$ tem aumento de $0,6 \%$. No entanto, conforme já discutido anteriormente, este foi um ano bastante atípico nas medidas da hidrógrafa, devido à distribuição homogênea da precipitação e à falta de chuvas intensas.

Os resultados médios dos coeficientes de eficiência Cns e Pbias para o período de validação podem ser classificados como não satisfatórios para a BHRL. Para a BHRM, o Cns 
é classificado como bom e o Pbias, como muito bom (Moriasi et al., 2007) (Tabela 4).

Tabela 4. Valores dos coeficientes de eficiência encontrados para o período de validação.

\begin{tabular}{lccccc}
\hline & \multicolumn{2}{c}{ BHRL } & & \multicolumn{2}{c}{ BHRM } \\
\cline { 2 - 3 } \cline { 5 - 6 } Cns & $08-09$ & $09-10$ & & $08-09$ & $09-10$ \\
Pbias & $-1,3$ & 0,71 & & 0,7 & 0,6 \\
\hline
\end{tabular}

Analisando-se o Cns de cada ano, verifica-se que, na BHRL, o modelo apresentou resultados bons para o ano 2009-2010 e uma estimativa ruim do ES no ano hidrológico 2008-2009. Salienta-se que, neste ano, a precipitação foi de $2.478 \mathrm{~mm}$, bem acima da média histórica. E, ao verificar-se a hidrógrafa deste período, vê-se que a lâmina total escoada (868 $\mathrm{mm}$ ) é praticamente igual à média para toda a série $(864 \mathrm{~mm})$. Resultado semelhante foi obtido com o Pbias, tendo o ano 2008-2009 apresentado uma grande superestimativa, e o ano seguinte com resultado que pode ser classificado como muito bom.

As características pedológicas e geomorfológicas da BHRL são bastante desafiadoras para a modelagem de processos hídricos. O relevo acidentado, com ravinamentos profundos e agudos, e pedoformas côncavo-côncavas, imprimem uma dinâmica de escoamento com ênfase na fase subsuperficial e subterrânea, para as quais são necessárias informações detalhadas destas camadas para uma modelagem mais acertada. Ademais, os solos rasos e afloramentos de rocha, normalmente, não são mapeados devido à escala dos mapas e à presença pontual destes fatores, o que implica em maiores incertezas na modelagem.

$\mathrm{Na} \mathrm{BHRM}$, os anos hidrológicos apresentaram comportamentos totalmente opostos. No primeiro ano hidrológico, o BALSEQ subestimou em 43\% (Pbias) o ES; já no segundo ano, o modelo superestimou o ES em 24\%. Apesar disso, o Cns indicou resultados satisfatórios para ambos os anos, o que significa que o erro médio da modelagem é pequeno em relação à variância dos dados observados. Porém, o volume total simulado apresentou elevado desvio percentual. Estas incertezas na modelagem com o BASLEQ são devidas principalmente à estimativa do escoamento superficial com o método CN-SCS.

Apesar de o uso do método CN-SCS apresentar falhas graves na modelagem do ES, os totais mensais apresentaram boa performance, de acordo com os coeficientes Cns e Pbias, sobretudo para intervalos de tempo maiores. Já que o foco do BALSEQ é a recarga do aquífero livre, imprecisões no montante diário ou instantâneo do ES não prejudicam seus resultados principais, pois o processo de recarga tem um compasso de tempo geralmente maior, da ordem de meses ou anos, a depender das características físico-hídricas da bacia hidrográfica, enquanto o ES comumente apresenta um tempo de concentração da ordem de dias ou semanas (Price, 2011). Portanto, o modelo fornece boas estimativas mensais para o ES e, portanto, boas estimativas de médio e longo prazo para a recarga direta.

\section{CONCLUSÃO}

O BALSEQ apresentou resultados consistentes na maioria dos casos. Os eventos para os quais o modelo teve resultados não satisfatórios, segundo os coeficientes utilizados, referem-se às anormalidades hidrológicas relacionadas à eventos extremos. Assim, o BALSEQ é mais recomendado para simulações de longa duração (mensal e anual) do que para eventos diários ou de curta duração.

A avaliação qualitativa, por meio de gráficos dos dados da hidrógrafa em comparação aos simulados, permitiu uma validação positiva dos valores de recarga obtidos com o 
BALSEQ, pois o modelo pôde prever com coerência, o comportamento temporal da Rp quando comparada ao EB.

A recarga potencial direta média para a BHRL foi estimada em $895 \mathrm{~mm}$, o que corresponde à 40\% da precipitação média anual. Para a BHRM a Rp média foi de 393,31 mm, ou $25 \%$ da precipitação média anual. Os valores de EB também apresentaram a mesma tendência, tendo maior participação na vazão do Ribeirão Lavrinha (76\%) quando comparado ao Ribeirão Marcela (40\%). Em ambas as bacias o componente com maior participação no balanço hídrico foi a evapotranspiração com 51,4\% na BHRL e 56,7\% na BHRM. Portanto, não só o excedente hídrico é responsável pela maior recarga observada na BHRL, como também as características fisiográficas e pedológicas desta bacia, sobretudo o predomínio de pedoformas côncavo-convexas que favorecem o escoamento subterrâneo.

\section{AGRADECIMENTOS}

Os autores agradecem à CAPES pela concessão da bolsa de mestrado, à FAPEMIG pelo apoio financeiro (processo CAG - PPM-00571-13) e ao CNPq. Este artigo foi derivado de parte da Dissertação de Mestrado do primeiro autor apresentada ao Programa de Pós Graduação em Recursos Hídricos em Sistemas Agrícolas da Universidade Federal de Lavras.

\section{REFERENCIAS}

ALLEN, R. G.; PEREIRA, L. S.; RAES, D.; SMITH, M. Crop evapotranspiration: Guidelines for computing crop requirements. Rome: FAO, 1998. 300p. (Irrigation and Drainage Paper, 56).

ALVARES, C. et al. Köppen's climate classification map for Brazil. Meteorologische Zeitschrift, v. 22, n. 6, p. 711-728, 2013. http://dx.doi.org/10.1127/09412948/2013/0507

ÁVILA, L. F.; MELLO, C. R.; SILVA, A. M. Estabilidade temporal do conteúdo de água em três condições de uso do solo, em uma bacia hidrográfica da região da Serra da Mantiqueira, MG. Revista Brasileira de Ciência do Solo, v. 34, p. 2001-2009, 2010. http://dx.doi.org/10.1590/S0100-06832010000600024

CAMARGO, R. A.; COUTO, E. A.; AlVES, L. G. S.; CAliJURI, M. L.; SILVA, M. D. F. M. Aplicação de modelo de balanço hídrico BALSEQ para estimativa da infiltração profunda em região cárstica Application of a water balance model for estimating deep infiltration in a karstic watershed. Revista Ambiente \& Água, v. 6, n. 3, p. 1-15, 2011. http://dx.doi.org/10.4136/ambi-agua.456

CHUNG, I.; KIM, N.; LEE, J.; SOPHOCLEOUS, M. Assessing distributed groundwater recharge rate using integrated surface water-groundwater modelling: application to Mihocheon watershed, South Korea. Hydrogeology Journal, v. 18, p. 1253-1264, 2010. http://dx.doi.org/10.1007/s10040-010-0593-1

COLLISCHONN, W.; FAN, F. M. Defining parameters for Eckhardt's digital baseflow filter. Hydrological Processes, v. 27, n. 18, p. 2614-2622, 2012. http://dx. doi.org/10.1002/hyp.9391 
CUTHBERT, M. O.; MACKAY, R.; NIMMO, J. R. Linking soil moisture balance and source-responsive models to estimate diffuse and preferential components of groundwater recharge. Hydrology and Earth System Science, v. 17, p. 10031019, 2013. http://dx.doi.org/10.5194/hess-17-1003-2013

ECKHARDT, K. How to construct recursive digital filters for baseflow separation. Hydrological Processes, v. 19, n. 2, p. 507-515, 15 Feb. 2005. http://dx. doi.org/10.1002/hyp.5675

GOMES, N. M.; MELLO, C. R.; SILVA, M.; BESKOW, S. Aplicabilidade do LISEM (Limburg soil erosion) para simulação hidrológica em uma bacia hidrográfica tropical. Revista Brasileira de Ciência do Solo, v. 32, p. 2483-2492, 2008. http://dx.doi.org/10.1590/S0100-06832008000600025

GOMES, M. A.; LANI, J. L.; COSTA, L. M.; PONTES, L. M.; FIGUEIREDO, N. A.; BARDALES, N. G. Solos, manejo e aspectos hidrológicos na Bacia Hidrográfica do Araújos, Viçosa - MG. Revista Árvore, v. 36, p. 93-102, 2012. http:// dx.doi.org/10.1590/S0100-67622012000100011

LOBO-FERREIRA, J. P. Mathematical model for the evaluation of the recharge of aquifers in semiarid regions with scarce (lack) hydrogeological data. In: EUROMECH, 143., 1981, Rotterdam. Proceedings... Rotterdam: [s.n.], 1981.

MOCKUS, V. Design hydrographs. In: UNITED STATES. Department of Agriculture. National engineering handbook. Washington, D.C.: NRCS, 1972. p. 1-50.

MORIASI, D.; ARNOLD, J.; VAN LIEW, M.; BINGNER, R.; HARMEL, R.; VEITH, T. Model evaluation guidelines for systematic quantification of accuracy in watershed simulations. Transactions of the Asabe, v. 50, n. 3, p. 885-900, 2007.

OLIVEIRA, A. S.; SILVA, A. M.; MELLO, C. R.; ALVES, G. J. Stream flow regime of springs in the Mantiqueira Mountain Range region, Minas Gerais State. Cerne, v. 20, n. 3, p. 343-349, 2014. http://dx.doi.org/10.1590/01047760201420031268

PEREZ-MARIN, A. M.; MENEZES, R. S. C. Ciclagem de nutrientes via precipitação pluvial total, interna e escoamento pelo tronco em sistema agroflorestal com Gliricidia sepium. Revista Brasileira de Ciência do Solo, v. 32, p. 2573-2579, 2008. http://dx.doi.org/10.1590/S0100-06832008000600034

PERKINS, K. S.; NIMMO, J. R.; MEDEIROS, A. C.; SZUTU, D. J.; VON ALLMEN, E. Assessing effects of native forest restoration on soil moisture dynamics and potential aquifer recharge, Auwahi, Maui. Ecohydrology, v. 7, p. 1437-1451, 2014. http://dx.doi.org/10.1002/eco.1469

PONTES, L. M.; COELHO, G.; MEllo, C. R.; SilVA, A. M.; OlIVEIRA, G. C. Análise de sensibilidade e avaliação da estrutura do modelo BALSEQ em condições distintas de clima, solo e vegetação. Revista Brasileira de Recursos Hídricos, v. 20, n. 1, p. 46-54, 2015. http://dx.doi.org/10.21168/rbrh.v20n1.p4654

PRICE, K. Effects of watershed topography, soils, land use, and climate on baseflow hydrology in humid regions: A review. Progress in Physical Geography, p. 128, 2011. http://dx.doi.org/10.1177/0309133311402714 
SCHAEFLI, B.; GUPTA, H. V. Do Nash values have value? Hydrological Processes, v. 21, p. 2075-2080, 2007. http://dx.doi.org/10.1002/hyp.6825

SIlVA, L. A.; SIlVA, A. M.; COELHO, G.; MELlO, C. R.; PEREIRA, D. R. Groundwater recharge estimate at Alto Rio Grande - MG Watershed. Engenharia Agrícola, v. 32, p. 1097-1108, 2012. http://dx.doi.org/10.1590/S010069162012000600011 